\title{
Research on the policy of withdrawing and merging rural Primary and secondary schools
}

\author{
Kexin Liu \\ (Guangdong University of Foreign Studies, Guangzhou, Guangdong, 510006, China)
}

\begin{abstract}
The policy of adjusting the layout of rural compulsory education schools (hereinafter referred to as "withdrawing points and merging schools"), which became a national policy in rural areas of China in 2001, was suspended in 2012.The starting point of this policy is to better popularize nine-year compulsory education in rural areas and promote the large-scale development of rural education.However, there are many problems in the process of implementing this policy, which leads to the deviation between the implementation result and the expected target in some provinces.This paper attempts to discuss the effect, reason and reflection of the policy of withdrawing and merging rural primary and secondary schools.

Keywords: Rural compulsory education; Remove the points and adjust them; The policy effect

Author's brief introduction : Kexin Liu, female, born in Huanggang, Hubei Province in October 1997, is a master of social work in Guangdong University of Foreign Studies. The main research direction is social organization and social governance.
\end{abstract}

DOI: $10.36012 /$ fhe.v2i1.1565

$\mathrm{T}$

he rural primary a nd secondary schools' withdrawal and merging is a policy based on the integration of educational resources, the reduction of management costs, the optimization of school layout, the improvement of rural teaching level and the promotion of urban and rural education equity. However, in the process of implementation, due to the lack of overall scientific planning and sufficient research before the implementation of the policy, it has caused some damage to education equity to a certain extent, and produced some other negative benefits. What are the problems, the reasons behind them and the solutions? This paper will be based on the relevant data and research results of relevant scholars.

\section{The implementation effect of the policy of removing and merging schools in rural areas}

In the 1990s, the effect of family planning gradually appeared, and the number of school-age children decreased. In order to integrate rural education resources, reduce management costs and optimize the layout of rural schools. Local governments began the movement of removing and merging rural primary and secondary schools. The decision on the reform and development of Basic Education promulgated by the State Council in 2001 is an important document of rural education reform. "Decision" document pointed out that "adjust the layout of rural compulsory education schools according to local conditions. According to the principle of primary school entrance nearby, junior middle school relatively concentrated, and optimizing the allocation of educational resources, the school layout should be reasonably planned and adjusted. Rural primary schools and teaching sites should be properly combined on the premise of facilitating students to enter school nearby. Necessary teaching points should be retained in areas with inconvenient transportation to prevent students from dropping out of school due to layout adjustment. The adjustment of school layout should be integrated with the renovation of dilapidated buildings, the standardization of schooling system, the development of urbanization, and the relocation of immigrants. The adjusted school buildings and other assets should be used for the development of education. Boarding schools may be set up where necessary and where conditions permit. " ${ }^{[1]} \mathrm{At}$ the national basic education work conference held in the same year, the rural primary and secondary school layout adjustment was 
listed as one of the six key tasks in the development of rural compulsory education. So far, the nationwide large-scale rural school layout adjustment started. The Ministry of education, the Ministry of Finance and the State Council have also issued a series of documents to vigorously promote the implementation of rural school layout adjustment ${ }^{[2]}$. What negative effects have been brought about by the implementation of the policy of removing and merging schools in rural areas?

\subsection{The rapid implementation of the policy of merging schools and schools has led to a rise in the dropout rate of rural primary schools.}

Some local governments have vigorously promoted the adjustment of rural schools' layout, and their pursuit of improving scale efficiency and merging schools has exceeded reasonable limits. During the 10 years from 2000 to 2010 , the number of rural primary schools decreased by more than $50 \%$, the number of rural primary schools decreased by 229400 , a decrease of $52.1 \%$, and the number of teaching centers decreased by 111000 , a decrease of $60 \%$. The number of rural junior high schools decreased by 10600 , or more than a quarter. On average, 63 primary schools, 30 teaching sites and 3 junior high schools will disappear every day. Almost every hour, four rural schools will disappear. At the same time, in the past 10 years, the number of rural primary school students decreased by 31.5349 million, a decrease of $37.8 \%$, and the number of rural junior high school students decreased by 16.44 million, a decrease of $26.97 \%{ }^{[3]}$. In some remote provinces, the speed of merging and withdrawing has reached an alarming level. For example, the number of primary schools in Inner Mongolia decreased from 13645 in 1995 to 2996 in 2010 (including nine-year consistent system schools), with a decrease rate of $78 \%$, The number of teaching points decreased from 8809 in 1995 to 466 in 2010, with a decrease rate of $95 \%$. The number of primary schools in Shanxi Province decreased from 33336 in 2000 to 10100 in 2010 (including nine-year consistent system schools), with a total reduction of $23236(69.7 \%)^{[4]}$. Due to the unreasonable adjustment of school layout in some areas and the blind merger of schools, the service radius of schools is too large and the distance between students to go to school is too far, which leads to an increase in the dropout rate of rural primary and secondary school students in remote areas ${ }^{[5]}$. If the policy is implemented too fast and exceeds the reasonable efficiency, it will not only deviate from the original goal of rural school layout adjustment, but also cause a rebound in the dropout rate.

\subsection{Increase the difficulty of primary school stu- dents in rural areas}

Some scholars have conducted field research in some areas after the implementation of the policy, and found that students will face many difficulties in going to school. Students in some areas can only go to the central school 10 kilometers away due to the withdrawal of the village primary school, and it even takes two or three hours to go to school on the way to school. In some mountainous areas of Guizhou and Guangxi, there will be many dangers on the mountain roads. As a result, it has the consequence of delaying enrollment and even dropping out of school. A large number of rural boarding schools have sprung up. As of 2010, the number of boarding students in primary and secondary schools in rural areas of China accounted for $24.32 \%$ of the total number of primary school students, of which the total number of primary school boarders reached 9800572 , accounting for $12.07 \%$ of the total number of primary school students, and the boarding rate of junior high school reached $47.89 \%{ }^{[6]}$. Due to the long distance, the junior primary school students have to choose to live in school, without their parents' company for a long time, which is not conducive to the physical and mental development of students. Students also need time to adapt to the new teaching methods and learning environment. It is not conducive to the study and growth of rural primary school students because of the long way to school or the residential life started in the lower grades.

\subsection{Increased the cost of rural family education}

As the distance between the family and the school becomes longer, the farmers need to bear the food or transportation expenses of the students in the central school, and in some boarding schools, they also need to bear the extra accommodation expenses. These costs undoubtedly increase the economic burden of farmers. According to a survey of rural areas in Central China, some boarding schools spend about 400 yuan per month for meals per month. In addition to other living expenses, it is not a small expense every month. As a primary school student's expense, it is no doubt difficult for rural parents who do not have fixed 
jobs and income to accept, and the cost paid by parents is far more than the meaning To some extent, the economic and living burden of rural parents has been aggravated by the free tuition and textbook fees of the rural education ${ }^{[7]}$. Sometimes the journey to school is too far away, and there is no dormitory built in the new central school. Rural families have to let an adult labor force rent a house near the school to take care of the lower grade pupils who can't live alone. The loss of farmland or migrant labor and the cost of renting and eating directly lead to the rise of rural family education costs, which also become an important reason for the rebound of dropout rate.

\section{Reflection on the implementation of cen- tralized education in rural areas}

\subsection{At the beginning of the policy, some scholars held a positive attitude}

At the beginning of the promulgation of the policy of centralized running schools in rural areas, some scholars hold a more positive attitude towards the policy of rural school layout adjustment. Centralized school running is conducive to rational distribution, making full use of educational resources, improving school running conditions and school environment, and improving the quality of rural teachers to meet the needs of people for high-level education. It is conducive to the implementation of quality education in rural areas and the improvement of the level and quality of rural compulsory education. It is also conducive to the internal management reform of rural primary and secondary schools, optimizing the structure of teachers, improving the management level of rural schools, making them more standardized, and finally narrowing the gap between urban and rural education level.

\subsection{The policy of centralized education needs ap- propriate conditions}

However, the implementation of the policy of centralized education in rural areas is subject to the above positive benefits, which requires appropriate economic foundation and geographical conditions. In plain areas and economically developed areas, the implementation of the policy has received good results. For example, in Heilongiiang region, there are enough funds to build school buildings and improve the corresponding teaching facilities after centralized school running. Another example is that Liangkou Town, Conghua City, Guangdong Province, has raised money from the foun- dation, which has provided sufficient financial guarantee for the centralized running of schools, as well as holding a meeting of students' parents to solicit opinions from all parties. However, in many poor rural areas, there is not enough funds to build centralized school supporting facilities, which will make the implementation of rural centralized school running policy lack of financial guarantee. In addition, some areas did not listen to the opinions and suggestions of the primary and secondary school students and their parents who are directly related to the implementation of the centralized school running policy, which not only deviates from the goal of the policy, but also brings a lot of negative effects. In some remote mountainous areas, even through full investigation and public opinion, due to the complex geographical environment and numerous mountains, the location of the final central school will cause some students to go to school inconveniently.

\subsection{Centralized education in rural areas has widened} the gap between urban and rural education

Some local governments have some "eager for quick success and instant benefit" mentality when implementing the school layout adjustment, and even regard the speed of merging and merging schools as the display of their political achievements. In the process of merging and merging, they did not conduct a full investigation on students' needs for schooling. Instead, they adopted a "one size fits all" promotion method and quantified indicators for school site merging. In the 1990s, the socialist market economy has radiated the vitality of the economic market, so the concept of efficiency first has also been spread to education. It is regarded as an important task to promote the development of urbanization and improve the scale efficiency of rural compulsory education by using centralized school running. However, some rural areas are not suitable for highly centralized school running due to geographical factors such as vast land, sparse population or rugged mountain roads. The principle of compulsory education nearby has been broken, and the appeal for popularization of rural compulsory education has been ignored to a certain extent in the movement of merging. The educational level of rural primary and secondary schools has once again widened the gap with that of urban primary and secondary schools. Due to the existence of intergenerational transmission effect of education, education has not played an impor- 
tant role in reducing social inequality, but has become a driving mechanism for progress and aggravating Urban-Rural Inequality due to its own inequality ${ }^{[8]}$. To a certain extent, the implementation of the policy of centralized education in rural areas has a negative impact on the educational rights of rural school-age children, and some of the teenagers who drop out of school will cause social problems such as poverty and crime. The gap between urban and rural education level is difficult to cross, which also aggravates the class solidification.

\section{The solution to the problem of merging schools with rural areas}

Due to the implementation of the policy of centralized running schools in rural areas, many adverse consequences and disputes have arisen. In September 2012, the general office of the State Council issued a document calling for a resolute ban on the blind withdrawal and merger of rural schools, which marks the suspension of the partial adjustment policy of rural schools since 2001. And 2020 will be a successful year of comprehensive poverty alleviation, and the new anti-poverty battle will focus on relative poverty. Among the factors that restrict rural development, the most critical point is the education level of rural population. How to improve the education level of rural schools and rural residents is an important problem to be solved in eliminating relative poverty and Rural Revitalization in the new era.

\subsection{The principle of fairness should be put in the first place in the implementation of centralized school running}

The policy of centralized running schools in rural areas should put fairness in the first place. Some provinces pursue the efficiency of policy implementation and ignore the significance of fairness, which leads to more negative benefits of the policy. In the process of adjusting the distribution of rural primary and secondary schools, the phenomenon of too fast or too large force of removing and running schools appears in many places. The implementation of policies at the grass-roots level places too much emphasis on the speed of removing points and schools, but ignores the importance and necessity of preliminary investigation and reasonable planning. Before the implementation of the policy, we should do full research on the implementation area of the policy, fully understand the local specific situation and listen to the voice of the public, especially need to investigate and respect the views of the stakeholders, primary and secondary school students and their families on the construction of central schools. The smooth implementation of rural centralized school also needs to fully investigate the local economic development and geographical environment, the number of school-age children and traffic conditions, the distance of primary and secondary school students and the educational investment of rural families for their children. Before the construction of the central school, the development of local culture and village is also taken into consideration. In short, before the construction of the central school, we need to have a full understanding of the local environment and social culture to ensure that the establishment of the central school is fair oriented.

\subsection{Taking decentralized school running as a sup- plement to centralized school running}

It is necessary to decentralize school running. Decentralized school running has been an indispensable form of running schools in China since ancient times. China has a vast territory, rural population living relatively scattered compared with the city, especially in the remote, poverty, special geographical environment, bad weather conditions, ethnic estrangement, religious beliefs and other prominent problems exist in the areas, decentralized school-running mode can ensure that the school-age children in these areas receive compulsory education nearby. On the contrary, it has a negative impact on the popularization level of compulsory educational administration in some areas which have not been fully investigated. In view of the above analysis, rural centralized school running should be adapted to local conditions and develop various forms of school running. In rural areas, a small-scale school running mode with good quality is conducive to the stability of rural education, and it can also ensure that primary and secondary school students in particularly poor areas complete compulsory education.

Although the rural centralized school running policy has been stopped, it is still implemented in some provinces. At present, China's financial expenditure on education has increased year by year. Under the situation that the rural central school has been established, rural compulsory education should start from students more. Therefore, a part of the financial 
expenditure can be used to improve the teaching environment and accommodation conditions of rural central schools, so as to ensure the physical and mental health of primary and secondary school students. In addition, in particularly remote and poverty-stricken areas, whether we can consider setting up teaching points so that school-age children in poverty-stricken areas can go to school nearby, so that they can learn better.

\section{References:}

[1] decision of the State Council on the reform and development of basic education[EB/OL](2001-05-29)[2012-12-27] http://www.edu.cn/20010907/3000665.shtml.

[2] Yang Dongping, Wang Shuai. From network extension, various forms of school running to the withdrawal and combination of schools: a rural compulsory education policy hovering between fairness and efficiency [J].Education Research of Tsinghua University.DOI:10.14138/j.1001-4519. 2013.05.004

[3] disappearing rural schools [n]. Social science journal, 2012-11-29(003).
[4] the data is from the China Education Statistics Yearbook of relevant years.

[5] Chu Weizhong, Zhang Yuhui. Analysis on the negative impact of "removing and merging schools" in rural compulsory education [J]. Teaching and management,2012(07):10-12.

[6] Zeng Xin. Research on the unbalanced development of compulsory education in counties after school layout adjustment [J]. Journal of central China Normal University (HUMANITIES AND SOCIAL SCIENCES),2014,53(02): 159-166.

[7] Li panqiang, Zeng Erqin, Yang Guohui. The game between fairness and efficiency: an investigation and Reflection on the withdrawal and merger of primary and secondary schools in rural areas in Central China [J]. Journal of $\mathrm{Hu}-$ nan University of Humanities and technology,2012 (04): 103-108.

[8] Liu Guichuan, Luo Yingchun. The impact of centralized resources on education investment behavior of rural households in remote and poverty-stricken mountainous areas: a case study of Guizhou Province [J]. Rural economy and science and technology,2008(09):45-46. 